\title{
Caracterização dos resíduos da polpa do maracujá-amarelo
}

\author{
Characterization of yellow passion fruit pulp wastes
}

\section{Eliana Monteiro Soares de Oliveira ${ }^{\mathrm{I}}$ Suelen Alvarenga Regis ${ }^{\mathrm{I}}$ Eder Dura de Resende ${ }^{\mathrm{I}}$}

\section{RESUMO}

\begin{abstract}
Neste trabalho, avaliou-se o rendimento em suco, arilo e sementes do maracujá-amarelo, para identificar o potencial de agregação de valor às sementes usadas na extração do óleo. Foram feitas medidas de massa, coloração da casca, tamanho e formato do fruto, rendimento em suco, sementes, arilo, número de sementes por fruto e umidade das sementes. Os dados foram interpretados por intervalo de confiança a $P \leq 0,05$ para amostras de uma população infinita de frutos. Verificou-se que o rendimento em suco aumentou com o amadurecimento, mas não foi influenciado pelo formato e tamanho. A proporção do resíduo total foi maior nos frutos maduros com o menor tamanho. $O$ rendimento de sementes foi menor nos frutos grandes, mas não foi alterado pelo formato, apresentando média de 4,23\% de semente. O conteúdo de óleo estimado nas sementes com $25,7 \%$ bs indica um potencial de produção de 64,84t de óleo por ano no estado do Rio de Janeiro.
\end{abstract}

Palavras-chave: Passiflora edulis f. Flavicarpa, resíduos da extração do suco, formato, tamanho do fruto.

\section{ABSTRACT}

This research evaluated the juice yield, arils and seeds of yellow passion fruits aiming to identify the potential of adding values for the seeds used in the oil extraction. It was measured the weight, peel color, size and shape of the fruit, juice yield, seeds, arils, number of seeds per fruit and humidity of seeds. The data were interpreted by confidence intervals at $P \leq 0.05$ for samples of an infinite population of fruits. It was verified that the juice yield increased with the ripening, but it was not changed by the shape and fruit size. The proportion of arils and seeds was higher in ripe fruits with smaller size. The seed yield was lower in bigger fruits, but it was not changed by the fruit shape, presenting average of $4.23 \%$ of seeds with $14.8 \%$ humidity. The estimated content of oil in seeds with 25.7 $\% d b$ indicates a production of $64.84 t$ of oil per year at the Rio de Janeiro state.

Key words: Passiflora edulis $f$. Flavicarpa, waste of juice extraction, shape, size of fruit.

\section{INTRODUÇÃO}

O Brasil é o maior produtor mundial de maracujá-amarelo e o maior exportador de suco concentrado (ARAUJO et al., 2005). As indústrias do Rio de Janeiro processam aproximadamente 7000t de maracujás por ano, sendo que $65 \%$ dessa matéria-prima não são aproveitadas (COELHO, 2008).

As sementes são ricas em fibras, minerais e lipídios, com boa quantidade de proteínas. As fibras insolúveis são predominantes (CHAU \& HUANG, 2004). As sementes podem ser utilizadas para a produção de óleos comestíveis ou para a indústria de cosméticos (KOBORI \& JORGE, 2005). Segundo FERRARI et al. (2004), a semente de maracujá possui $25,7 \%$ de óleo e teor protéico de 15,62\%, sendo também fonte de fibras. O óleo apresenta predominância de ácido graxo oléico e linoléico.

Na industrialização do maracujá, utilizam-se frutos com diferentes tamanhos, formatos e estádios de maturação e, normalmente, apenas o suco é

'Programa de Pós-graduação em Produção Vegetal, Laboratório de Tecnologia de Alimentos, Centro de Ciências e Tecnologias Agropecuárias (CCTA), Universidade Estadual do Norte Fluminense Darcy Ribeiro (UENF), Av. Alberto Lamego, 2000, Parque Califórnia, 28013-602, Campos dos Goytacazes, RJ, Brasil. E-mail: eresende@uenf.br. *Autor para correspondência 
aproveitado, descartando-se o resíduo de sementes com arilos. Agregar valor a esses subprodutos é de interesse econômico, científico e tecnológico (FERRARI et al., 2004). Neste trabalho, caracterizaramse o rendimento em suco e a proporção de arilo e de sementes do maracujá com diferentes estádios de maturação, formatos e tamanhos, com o objetivo de quantificar os resíduos da extração do suco e projetar o potencial de aproveitamento das sementes para extração do óleo.

\section{MATERIAL E MÉTODOS}

Os frutos de maracujazeiro (Passiflora edulis Sims f. flavicarpa) foram colhidos em pomar comercial de Campos dos Goytacazes (RJ) entre novembro de 2008 e janeiro de 2009 , com temperatura média de $23,93 \pm 0,84^{\circ} \mathrm{C}$, umidade relativa de $84,87 \pm 0,99 \%$ e precipitação pluviométrica de $339 \pm 182,40 \mathrm{~mm}$. O solo é do tipo Argissol Amarelo, desenvolvido a partir de sedimentos terciários, horizonte B textural com camada superficial arenosa e relevo suavemente ondulado, caracterizando as condições edafoclimáticas dos locais onde são cultivados os maracujazeiros na região norte fluminense (CARVALHO et al., 2000).

Quarenta repetições de frutos para cada tratamento foram padronizadas em três estádios de maturação, dois tamanhos (grande e pequeno) e dois formatos (ovalado e redondo), mantendo a mesma razão comprimento/largura (razão $\mathrm{C} / \mathrm{L}$ ). Os estádios de maturação compreenderam frutos com a casca verde clara, frutos com início de coloração amarela e frutos totalmente amarelos. A cor da casca foi caracterizada pelo Colorímetro HunterLab MiniScan Spectrophotometer, utilizando iluminante D65, ângulo de observação de $10^{\circ}$ no sistema $\mathrm{L}, \mathrm{a}, \mathrm{b}$. As leituras foram realizadas em pontos equidistantes das faces exposta e não-exposta do fruto ao sol na planta. A proporção de cor amarela na casca foi obtida conforme SILVA et al. (2008).

Os frutos foram mantidos em câmara fria a $12^{\circ} \mathrm{C}$ e $90 \%$ UR por até 36 horas para preservar a qualidade e viabilizar o processamento. Os maracujás foram pesados em balança semi-analítica e cortados para remoção e pesagem da polpa bruta, sendo processada em homogeneizador Britânia no módulo "pulsar" para preservar as sementes. O suco foi extraído em prensa manual com auxílio de uma tela filó de $1,0 \mathrm{~mm}$, separando a quantidade de resíduo que foi pesado em balança analítica. A quantidade de suco foi obtida pela diferença entre a massa de polpa bruta e o resíduo bruto, normalizada para $100 \mathrm{~g}$ de fruto.

O resíduo foi imerso em água e aquecido em forno microondas por $5 \mathrm{~min}$, lavado posteriormente em peneira sob água corrente. As sementes foram mantidas em secador a $45^{\circ} \mathrm{C}$ por $25 \mathrm{~min}$ e resfriadas por $5 \mathrm{~min}$ antes da pesagem final em balança analítica. A umidade foi determinada em estufa a $105^{\circ} \mathrm{C}$ por 24 horas, segundo método da AOAC (1998). A massa de sementes foi normalizada para $100 \mathrm{~g}$ de fruto. A quantidade de arilo foi determinada pela diferença entre a massa do resíduo bruto e a massa das sementes, normalizada para $100 \mathrm{~g}$ de fruto. Determinou-se também o número de sementes de cada fruto.

Para os três estádios de maturação, utilizaram-se frutos grandes e de formato ovalado, com 10,3 a 10,5cm de comprimento longitudinal (C) por 8,2 a $8,4 \mathrm{~cm}$ de largura $(\mathrm{L})$ de região equatorial (razão $\mathrm{C} / \mathrm{L}=1,3$ ). Para avalair o efeito de formato, foram utilizados frutos totalmente amarelados de tamanho grande, comparando frutos de formato ovalado (razão $\mathrm{C} / \mathrm{L}=1,3$ ) e formato redondo, medindo 8,1 a $8,3 \mathrm{~cm}$ de comprimento (razão $\mathrm{C} / \mathrm{L}=1,0)$. Na avaliação do efeito de tamanho, foram comparados os frutos amarelos grandes e de formato ovalado com relação aos frutos menores de mesmo formato ovalado, medindo 8,2 a $8,4 \mathrm{~cm}$ de comprimento longitudinal por 6,5 a $6,7 \mathrm{~cm}$ de largura equatorial (razão $\mathrm{C} / \mathrm{L}=1,30)$.

Utilizou-se o método de amostragem simples ao acaso (ASA), com $95 \%$ de probabilidade de ocorrência em uma população infinita de maracujásamarelos. As médias foram comparadas utilizando-se o Teste ' $t$ ' para o intervalo de confiança. A amostra ideal foi dimensionada para população infinita de frutos, considerando, além do nível de significância de 5\%, o desvio de $10 \%$ em torno da média amostral, para todas as características analisadas.

\section{RESULTADOS E DISCUSSÃO}

Verificou-se que a amostragem de 40 frutos foi representativa de uma população infinita de maracujás-amarelos, com $95 \%$ de probabilidade e $10 \%$ de desvio em torno da média amostral, para todas as variáveis analisadas (Tabela 1).

Segundo o padrão de classificação do CEAGESP (COELHO, 2008), os maracujás grandes utilizados neste trabalho são do tipo Extra 3A. Os frutos de menor tamanho, pesando 145,78g, são do tipo Extra A (Tabela 2). Os frutos de maior tamanho, utilizados neste trabalho, são mais pesados do que os frutos de seis cultivares estudadas por Melo (1999), que variaram de $98,98 \mathrm{~g}$ a $129,97 \mathrm{~g}$. A maioria das progênies avaliadas por NASCIMENTO et al. (2003) apresentou frutos com peso superior à média de $161,6 \mathrm{~g}$, variando de $118,8 \mathrm{a}$ $226,7 \mathrm{~g}$.

No padrão intermediário, os frutos apresentaram $28,91 \pm 3,93 \%$ da casca amarelada e os 
Tabela 1 - Tamanho mínimo de amostra representativa de uma população infinita de maracujá-amarelo para caracterização do fruto, rendimento em suco, semente e arilo em função do estádio de maturação, formato e tamanho (Probabilidade de 95\% e desvio de $10 \%$ em torno da média amostral).

\begin{tabular}{|c|c|c|c|c|c|}
\hline \multirow{2}{*}{ Variáveis } & \multicolumn{5}{|c|}{ - } \\
\hline & $\begin{array}{l}\text { Verde/Claro } \\
\text { Grande - Ovalado }\end{array}$ & $\begin{array}{l}\text { Intermediário } \\
\text { Grande - Ovalado }\end{array}$ & $\begin{array}{c}\text { Maduro } \\
\text { Grande - Ovalado }\end{array}$ & $\begin{array}{l}\text { Maduro } \\
\text { Grande - Redondo }\end{array}$ & $\begin{array}{l}\text { Maduro } \\
\text { Médio - Ovalado }\end{array}$ \\
\hline Massa do fruto $(\mathrm{g})$ & $4,98(10,99)$ & $3,67(9,44)$ & $4,90(10,90)$ & $3,91(9,74)$ & $7,44(13,43)$ \\
\hline Comprimento $-\mathrm{C}(\mathrm{cm})$ & $0,03(0,81)$ & $0,04(1,04)$ & $0,03(0,86)$ & $0,05(1,14)$ & $0,07(1,35)$ \\
\hline Largura - L (cm) & $0,04(1,02)$ & $0,06(1,17)$ & $0,05(1,05)$ & $0,05(1,07)$ & $0,09(1,47)$ \\
\hline Razão (C/L) & $0,05(1,13)$ & $0,11(1,65)$ & $0,08(1,44)$ & $0,09(1,48)$ & $0,20(2,23)$ \\
\hline cor amarela casca $(\%)$ & $* *$ & $73,87(42,34)$ & $10,23(15,76)$ & $3,66(9,42)$ & $2,83(8,28)$ \\
\hline Rendimento em suco (\%) & $* *$ & $14,76(18,93)$ & $14,07(18,48)$ & $13,07(17,81)$ & $16,13(19,79)$ \\
\hline Rendimento resíduo (\%) & $* *$ & $10,91(16,27)$ & $5,33(11,38)$ & $4,49(10,43)$ & $6,32(12,38)$ \\
\hline Rendimento sementes (\%) & $* *$ & $23,95(24,11)$ & $13,09(17,82)$ & $10,25(15,77)$ & $14,44(18,72)$ \\
\hline Quantidade sementes (\%) & $* *$ & $26,93(25,57)$ & $15,08(19,13)$ & $13,23(17,92)$ & $29,98(26,52)$ \\
\hline Peso de cada semente (g) & $* *$ & $8,72(14,54)$ & $3,48(9,19)$ & $3,36(9,03)$ & $7,43(13,43)$ \\
\hline
\end{tabular}

* Valores entre parênteses representam o Coeficiente de Variação (\%) das medidas.

** No estádio de coloração verde-claro, não ocorreu formação suficiente de polpa.

frutos maduros $84,56 \pm 4,27 \%$ de casca amarelada. SILVA et al. (2008) verificaram que os maracujás da safra de verão alcançam maturação adequada quando atingem $65 \%$ de coloração amarela. Portanto, os frutos do estádio intermediário não estavam com maturidade fisiológica plena. Os frutos de formato ovalado ou redondo apresentaram o mesmo padrão de cor, com média de $87,79 \pm 3,51 \%$. No entanto, os frutos menores apresentaram $92,39 \pm 2,46 \%$ de coloração amarelada, diferindo dos frutos grandes $(84,56 \pm 4,28 \%)$. Contudo, tais diferenças de coloração da casca não interferem na avaliação do rendimento de polpa e resíduos dos frutos com mais de $65 \%$ de cor amarela, conforme verificado por SILVA et al. (2008).

No estádio verde-claro, os frutos não apresentaram rendimento significativo de suco, pois estavam imaturos (Figura 1). No estádio intermediário, o rendimento em suco foi de $29,89 \pm 1,82 \%$, sendo inferior ao dos frutos maduros $(36,63 \pm 2,17 \%)$. O rendimento em suco não foi influenciado pelo formato dos frutos (Figura 1). Nos maracujás redondos, o rendimento em suco foi de $35,76 \pm 2,04 \%$ e, nos maracujás ovalados, foi de $36,63 \pm 2,17 \%$. ALBUQUERQUE et al. (2002) verificaram correlações diretas para porcentagem de suco e peso da polpa com relação ao diâmetro e comprimento do fruto, respectivamente, porém não padronizaram o formato dos frutos.

Comparando os dois padrões de tamanho (Figura 1), verificou-se o mesmo rendimento em suco entre frutos grandes $(36,63 \pm 2,17 \%)$ e menores $(35,75 \pm 2,27 \%)$. Isso contrasta com as observações de COELHO (2008), que encontrou maior rendimento nos frutos grandes $(37,19 \pm 2,57 \%)$ do que nos frutos menores $(21,96 \pm 2,46 \%)$. Essa diferença pode estar relacionada com a época de colheita, visto que no trabalho de COELHO (2008) foram utilizados frutos da safra de inverno (pouca chuva e menores temperaturas). Ao contrário, os frutos deste trabalho

Tabela 2 - Valores médios de massa, comprimento (C), largura (L) e razão C/L em função do estádio de maturação, formato e tamanho dos maracujás-amarelos.

\begin{tabular}{lcccc}
\hline Padrões & Massa $(\mathrm{g})$ & Comprimento $(\mathrm{cm})$ & Largura $(\mathrm{cm})$ & Razão $(\mathrm{C} / \mathrm{L})$ \\
\hline Verde claro - Grande ovalado & $255,84( \pm 9,03)$ & $10,39( \pm 0,03)$ & $8,30( \pm 0,03)$ & $1,25( \pm 0,01)$ \\
Intermediário - Grande ovalado & $275,81( \pm 8,35)$ & $10,39( \pm 0,03)$ & $8,30( \pm 0,03)$ & $1,25( \pm 0,01)$ \\
Maduro - Grande ovalado & $260,47( \pm 9,12)$ & $10,37( \pm 0,03)$ & $8,32( \pm 0,03)$ & $1,25( \pm 0,01)$ \\
Maduro - Grande redondo & $227,04( \pm 7,09)$ & $8,20( \pm 0,03)$ & $8,20( \pm 0,03)$ & $1,00( \pm 0,01)$ \\
Maduro - Médio ovalado & $145,78( \pm 6,28)$ & $8,32( \pm 0,04)$ & $6,60( \pm 0,03)$ & $1,26( \pm 0,01)$ \\
\hline
\end{tabular}

Os valores entre parênteses representam os intervalos de confiança em nível de 5\%. 


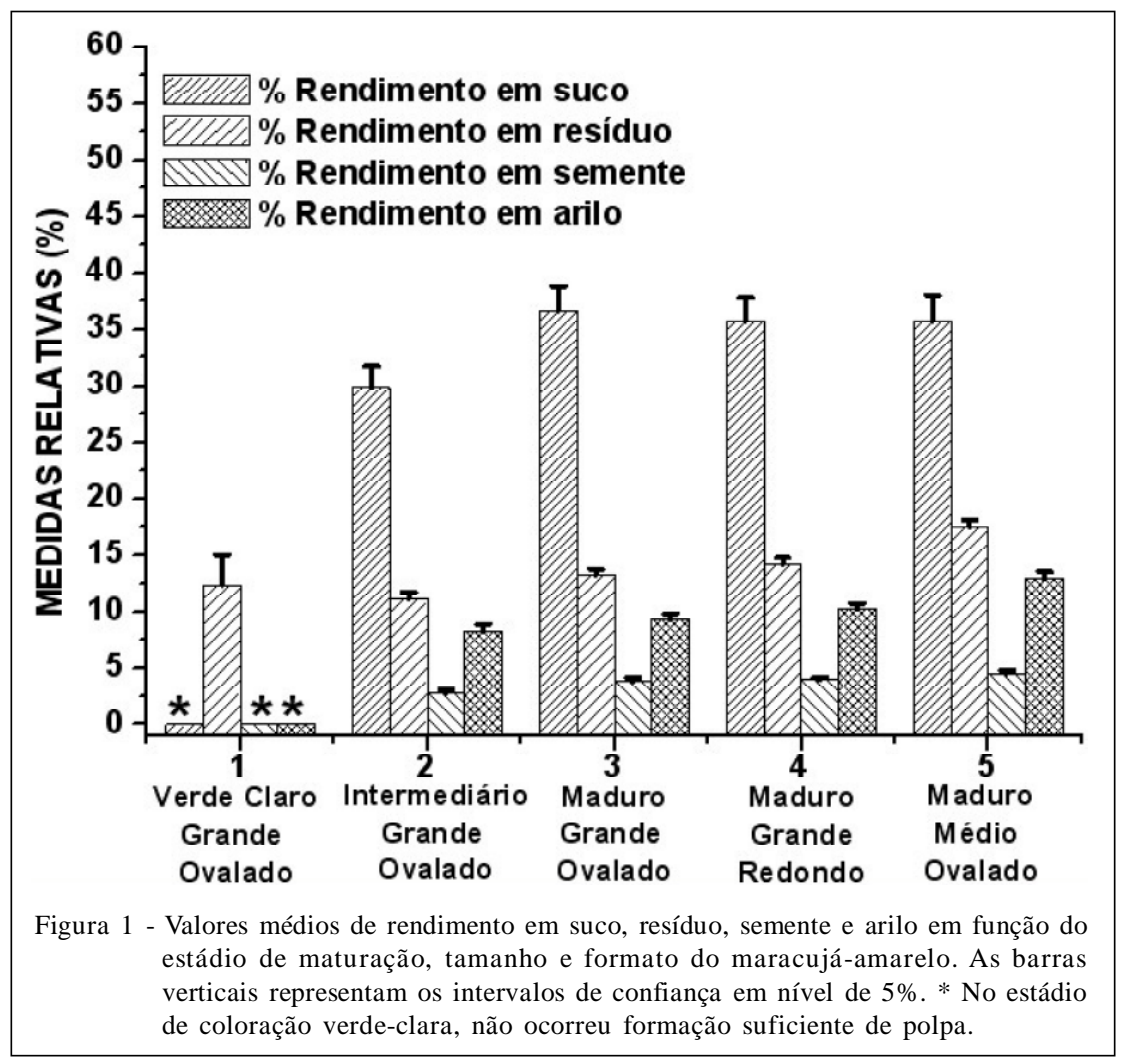

foram colhidos em época de chuvas intensas e com maiores temperaturas, favorecendo a disponibilidade de água na polpa e, consequentemente, o rendimento em suco.

No estádio verde-claro, não se quantificaram os resíduos porque os frutos estavam imaturos, em fase de desenvolvimento das sementes. O rendimento de arilo nos frutos maduros $(9,39 \pm 0,42 \%)$ foi maior do que no estádio intermediário $(8,30 \pm 0,61 \%)$, ocorrendo o incremento de arilo com o desenvolvimento das sementes imaturas (Figura 1). O resíduo bruto de arilo com sementes foi de $13,31 \pm 0,49 \%$ e $11,15 \pm 0,58 \%$, respectivamente.

O formato dos frutos não alterou $\mathrm{o}$ rendimento de resíduo bruto, com média de 13,8 $\pm 0,5 \%$ (Figura 1). COELHO (2008) encontrou 11,5\% em frutos de padrões semelhantes aos deste trabalho. Tais proporções de resíduo bruto explicam as diferenças de rendimento em suco entre as duas pesquisas. O rendimento de arilo foi maior nos frutos redondos $(10,29 \pm 0,43 \%$,$) do que nos frutos ovalados$ $(9,39 \pm 0,42 \%)$. Ocorreu também uma tendência de menor número de sementes nos frutos redondos (Figura 2), indicando que a maior proporção de arilo foi devido ao maior tamanho das vesículas que contém o suco. $\mathrm{Na}$ análise do tamanho, verificou-se que o rendimento de resíduo bruto para os frutos menores $(17,46 \pm 0,69 \%)$ foi expressivamente maior do que nos frutos grandes $(13,31 \pm 0,49 \%)$, justificando a igualdade de rendimento em suco entre os dois padrões.

Após a remoção do arilo e secagem da água superficial das sementes, verificou-se que o conteúdo de umidade das sementes nos frutos maduros foi de $14,83 \pm 1,37 \%$ (bu). O número de sementes foi maior nos frutos maduros $\left(401,37 \pm 24,64\right.$ sementes fruto $\left.^{-1}\right)$ do que na maturação intermediária $(297,40 \pm 24,40$ sementes fruto $\left.^{-1}\right)$. No estádio intermediário, as sementes imaturas de coloração branca foram descartadas (Figura 2). O rendimento de sementes aumentou de $2,85 \pm 0,22 \%$ no estádio intermediário para 3,92 $\pm 0,22 \%$ nos frutos maduros (Figura 1). No entanto, as sementes não mostraram diferenças no peso de cada uma entre esses

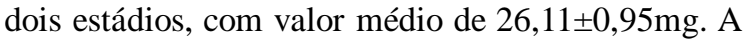
proporção entre o número de sementes (NS) e o rendimento em suco (RS) não foi alterada pelo estádio

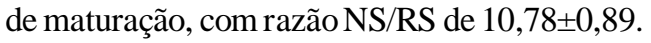

A época de produção influencia no número de sementes por fruto. $\mathrm{Na}$ época de moderadas temperatura e precipitação pluviométrica (Outubro a Dezembro), ocorre maior número de sementes do que na época mais seca, variando de 198 a 300, com média de 248 sementes/fruto (NASCIMENTO et al., 1999). 


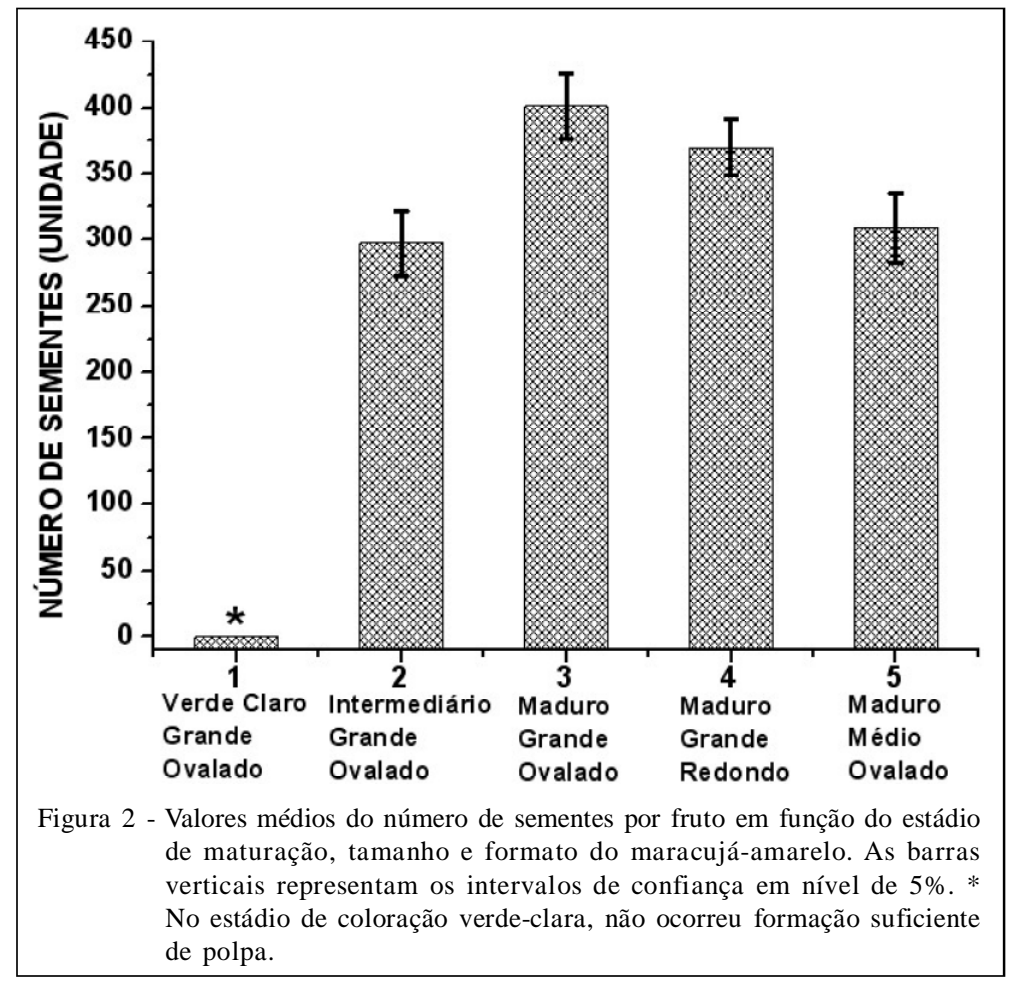

Em 20 progênies de maracujazeiro-amarelo, a média foi de 281 sementes fruto $^{-1}$, variando de 162 a 430 sementes fruto $^{-1}$ (NASCIMENTO et al., 2003). De acordo com FORTALEZA et al. (2005), o número de sementes é influenciado pelo genótipo de maracujá, variando de 126 a 228 sementes fruto ${ }^{-1}$.

$\mathrm{O}$ peso médio de sementes fruto $^{-1}$ para os maracujás grandes foi de $10,23 \mathrm{~g}$ fruto $^{-1}$, ao passo que para os frutos menores foi de $6,71 \mathrm{~g}$ fruto $^{-1}$. Esses valores apresentam as mesmas magnitudes daqueles obtidos por COSTA et al. (2001). Os frutos grandes apresentaram maior quantidade de sementes $(401,37 \pm 24,64)$ do que os frutos menores $(309,43 \pm 26,34)$ (Figura 2). A massa de cada semente nos frutos menores $(21,73 \pm 0,94 \mathrm{mg})$ foi inferior à dos frutos grandes $(25,50 \pm 0,75 \mathrm{mg})$. O resíduo bruto dos frutos menores foi superior ao dos frutos grandes, e a proporção de arilo foi mais significativa do que a de sementes, uma vez que o número de sementes é menor e possui menor massa.

Os frutos maiores apresentaram maior proporção entre número de sementes e rendimento em suco (razão NS/RS igual a 11,15 $\pm 0,73$ ) do que os frutos menores (razão NS/RS igual a $8,80 \pm 0,68$ ). Isso mostra que os frutos menores produziram mais suco por semente e uma maior proporção de arilo (maior tamanho das vesículas de suco). Os frutos redondos apresentaram tendência de menor número de sementes
$(370,17 \pm 21,29)$ do que os frutos ovalados $(401,37 \pm 24,64)$ (Figura 2). Isso pode ter ocorrido devido ao menor tamanho dos frutos (Tabela 2). A massa da semente não foi influenciada pelo formato, com média de $24,89 \pm 0,72 \mathrm{mg}$. Os frutos redondos apresentaram uma tendência de menores valores da Razão NS/RS $(10,53 \pm 0,61)$ do que os frutos ovalados $(11,15 \pm 0,73)$ devido à tendência de menor número de sementes fruto ${ }^{-1}$.

Para se ter uma projeção da quantidade de óleo obtida a partir do processamento de 7.000t anuais de maracujá pelas indústrias do estado do Rio de Janeiro (COELHO, 2008), estima-se uma produção de 296,1t de sementes com $14,8 \%$ de umidade, considerando um rendimento médio de sementes de $4,23 \%$ (p/p). Isso gera $64,84 t$ de óleo por ano a partir de sementes com conteúdo aproximado de $25,7 \%$ bs, segundo dados obtidos por FERRARI et al. (2004), além de 215,47t de torta desengordurada com $10 \%$ bu de umidade, que podem ser aplicadas na fabricação de rações para animais.

\section{CONCLUSÃO}

Concluiu-se que o rendimento em suco aumentou com o estádio de maturação do maracujá, mas não foi influenciado pelo formato e tamanho. A proporção do resíduo total foi maior nos frutos maduros com o menor tamanho. O rendimento de sementes foi menor nos frutos grandes, mas não foi alterado pelo 
formato, apresentando média de $4,23 \%$ de sementes com $14,8 \%$ de umidade.

\section{AGRADECIMENTOS}

Ao Conselho de Desenvolvimento Científico e Tecnológico ( $\mathrm{CNPq}$ ), pelos recursos financiados ao projeto (CTAGRO) - Edital n.04/2006 - Proc. 554408/2006-6 e Bolsa de Produtividade em Inovação Tecnológica; ao Sr. Jéferson, pela matéria-prima; a Universidade Estadual do Norte Fluminense Darcy Ribeiro (UENF) e a Fundação Carlos Chagas Filho de Amparo à Pesquisa do Estado do Rio de Janeiro (FAPERJ), pela bolsa de pesquisa.

\section{REFERÊNCIAS}

ALBUQUERQUE, A.S. et al. Possibilidade de seleção indireta para peso do fruto e rendimento em polpa em maracujá (Passiflora edulis Sims). In: CONGRESSO BRASILEIRO DE FRUTICULTURA, 17., 2002, Belém. Anais... Belém: Embrapa, 2002. CD-ROOM.

A.O.A.C. International. Official Methods of Analysis of AOAC International. 16.ed. Gaithersburg, 1998. 1025p.

ARAUjO, J.L.P. et al. Análise do custo de produção e rentabilidade do maracujá explorado na região do submédio do São Francisco. Petrolina - PE: Ministério da Agricultura, Pecuária e Abastecimento, 2005. ISSN 1808-9984. (Comunicado Técnico 122).

CARVALHO, A.J.C. et al. Adubação nitrogenada e irrigação no maracujazeiro-amarelo. I-Produtividade e qualidade dos frutos. Pesquisa Agropecuária Brasileira, Brasília, v.35, n.6, p.1101-1108, 2000. Disponível em: <http://www.scielo.br/pdf/ pab/v35n6/4664.pdf>. Acesso em: 03 out. 2009. doi: 10.1590/ S0100-204X2000000600005.

COELHO, A.A. Caracterização física e química dos frutos em função do tamanho e estádio de amadurecimento do maracujá-amarelo (Passiflora edulis f. flavicarpa Degener). 2008. 126f. Dissertação (Mestrado em Produção Vegetal) Universidade Estadual do Norte Fluminense Darcy Ribeiro, UENF, Campos dos Goytacazes, RJ.

CHAU, C.F.; HUANG, Y.L. Characterization of passion fruit seed fibres - a potential fibre source. Food Chemistry, Reading (UK), v.85, p.189-194, 2004.
FERRARI, R.A. et al. Caracterização de subprodutos da industrialização do maracujá - Aproveitamento das Sementes. Revista Brasileira de Fruticultura, Jaboticabal, v.26, n.1, p.101-102, 2004. Disponível em: <http://www.scielo.br/pdf/ rbf/v26n1/a27v26n1.pdf >. Acesso em: 06 jun. 2009. doi: 10.1590/S0100-29452004000100027.

FORTALEZA, J.M. et al. Características físicas e químicas em nove genótipos de maracujá-azedo cultivado sob três níveis de adubação potássica. Revista Brasileira de Fruticultura, Jaboticabal, v.27, n.1, p.124-127, 2005. Disponível em: <http:/ /www.scielo.br/pdf/rbf/v31n2/v31n2a24.pdf >. Acesso em: 20 set. 2009. doi: 10.1590/S0100-29452009000200024.

KOBORI, C.N.; JORGE, N. Caracterização dos óleos de algumas sementes de frutas como aproveitamento de resíduos industriais. Ciência e Agrotecnologia, Lavras, v.9, n.5, p.1008-1014, 2005. Disponível em: <http://www.scielo.br/pdf/cagro/v29n5/ a14v29n5.pdf>. Acesso em: 05 jul. 2009.

MELO, K.T. Comportamento de seis cultivares de maracujazeiro-amarelo (Passiflora edulis Sims f. flavicarpa Deg.) em Vargem Bonita, no Distrito Federal. 1999. $75 \mathrm{f}$. Dissertação (Mestrado em Ciências Agrárias) - Faculdade de Agronomia e Medicina Veterinária, Universidade de Brasília, DF.

NASCIMENTO, T.B. et al. Características físicas do maracujáamarelo produzido em diferentes épocas. Pesquisa Agropecuária Brasileira, Brasília, v.34, n.12, p.2353-2358, 1999. Disponível em: <http://www.scielo.br/pdf/pab/v34n12/ 6940.pdf>. Acesso em: 20 jan. 2009. doi: 10.1590/S0100204X1999001200023.

NASCIMENTO, W.M.O. et al. Seleção de progênies de maracujazeiro-amarelo (Passiflora edulis f. flavicarpa) quanto à qualidade de frutos. Revista Brasileira de Fruticultura, Jaboticabal, v.25, n.1, p.186-188, 2003. Disponível em: <http:/ /www.scielo.br/pdf/rbf/v25n1/a52v25n1.pdf>. Acesso em: 19 jan. 2009. doi: 10.1590/S0100-29452003000100052.

SILVA, T.V. et al. Determinação da escala de coloração da casca e do rendimento em suco do maracujá-amarelo em diferentes épocas de colheita. Revista Brasileira de Fruticultura, Jaboticabal, v.30, n.4, p.880-884, 2008. Disponível em: <http:/ /www.scielo.br/pdf/rbf/v30n4/a07v30n4.pdf>. Acesso em: 05 fev. 2009. doi: 10.1590/S0100-29452008000400007. 